\title{
Does bile reflux reduce Helicobacter pylori gastritis?
}

\author{
Ezgi Kıran Taşc1 ${ }^{1 \oplus}$, Miray Karakoyun ${ }^{1 \oplus}$, Murat Sezak $^{2 \oplus}$, Başak Doğanavsargil ${ }^{2 \odot}$, \\ Funda Çetin ${ }^{1 \odot}$, Sema Aydoğdu ${ }^{1 \odot}$ \\ Departments of ${ }^{1}$ Pediatric Gastroenterology, Hepatology and Nutrition and ${ }^{2}$ Pathology, Ege University Faculty of Medicine, İzmir, \\ Turkey.
}

\begin{abstract}
Background. Chronic abdominal pain is a frequent childhood complaint. This study aims to determine the relationship between bile reflux, which is increasing with the growth in packaged food consumption resulting from the changing food industry, and Helicobacter pylori gastritis.
\end{abstract}

Methods. In this retrospective study, 804 cases where there was an endoscopic examination for abdominal pain were included. We recorded the patients' age, sex, and macroscopic and microscopic endoscopic findings. Patients with chronic diseases were excluded.

Results. Our study included 804 cases. Of patients, $61.8 \%$ were female and $38.2 \%$ were male. The mean age was $11.56 \pm 4.14$ years. The Helicobacter pylori gastritis rate was found to be $22.3 \%$ among all patients. Bile reflux was seen in $192(23.9 \%)$ patients. Only $27(14.1 \%)$ of the 192 patients had Helicobacter pylori positivity ( $\mathrm{p}=0.002)$.

Conclusions. Helicobacter pylori gastritis is less common among patients with bile reflux. In another study conducted in our outpatient clinic before the 2000s, the frequency of Helicobacter pylori gastritis was found to be $40 \%$, but after 2000 this rate decreased to $22.3 \%$ due to bile reflux caused by the changing food industry. This result may be explained by the bactericidal effects of bile acids.

Key words: bile reflux, gastritis, Helicobacter pylori.

Chronic abdominal pain is one of the most frequent complaints of childhood and adulthood. It is associated with poor quality of life and psychosocial deprivation. ${ }^{1}$ Frequency ranges from $0.3-19 \%$ among school children and most of these cases have no organic pathology. ${ }^{2,3}$

Helicobacter pylori $(\mathrm{Hp})$ is a gram-negative bacteria colonizing the human stomach, and which can cause many gastrointestinal diseases. ${ }^{4}$ The prevalence of $\mathrm{Hp}$ varies worldwide and is affected by many factors such as age, ethnic group, and geographic and socioeconomic conditions. ${ }^{5}$ Most people are colonized with Hp in early childhood. ${ }^{4}$ Only $10-20 \%$ of these have the occurrence of gastroduodenal diseases. ${ }^{5}$

\section{Ezgi Kıran Taşcı \\ ezgikiran@gmail.com}

Received 15th October 2020, revised 9th January 2021, 23rd February 2021, 23rd April 2021,

accepted 16th May 2021.
Although endoscopy is primarily recommended for the diagnosis of $\mathrm{Hp}$ infection, urea breath test, and fecal Hp antigen evaluation are noninvasive tests that can be used. ${ }^{6}$

Bile reflux occurs by retrograde bile movement to the stomach. ${ }^{7}$ Bile in the stomach causes clinical symptoms, endoscopically observed macroscopic changes, and histopathological chemical gastritis. There is no gold standard for the diagnosis of bile reflux. ${ }^{8,9}$ Bile reflux is divided into primary and secondary reflux. Primary bile reflux occurs without gastric surgery, while secondary bile reflux is usually seen after surgery. Bile bladder dysfunction, gastric, and duodenal dysmotility are risk factors for primary bile reflux. ${ }^{10}$ Bile is a strong alkali and causes chemical irritation to the gastric mucosa by changing the gastric $\mathrm{pH}$ balance. Bile acids have antibacterial action against Hp. ${ }^{11}$ This study aims to determine the relationship between bile reflux and $\mathrm{Hp}$ gastritis 
and to show that bile reflux has increased due to the changing food industry and that this may have caused a decrease in Hp infection.

\section{Material and Methods}

Our study was retrospective, and data were taken from patients' files. Patients who applied to our pediatric gastroenterology clinic with abdominal pain and who were among the 804 cases that had undergone endoscopic examination between 2000-2019 were included. Patients with accompanying chronic diseases, alarm symptoms like diarrhea, bloody stool, growth retardation, persisting fever, elevated acute-phase reactant levels, and during followup, those who were diagnosed with Celiac disease and Familial Mediterranean Fever were excluded.

Diagnosis of bile reflux was made when we endoscopically observed bile in the stomach or detection retrograde bile flowed from the duodenum to the stomach. Patients with secondary bile reflux were excluded from the study.

We recorded the patients' age and sex and their macroscopic and microscopic endoscopic findings. The diagnosis of $\mathrm{Hp}$ infection was made by a positive rapid urease test or a positive culture result in addition to positive histopathology according to ESPGHAN guidelines. ${ }^{12}$ At least 6 gastric biopsies (antrum and corpus) were taken for the diagnosis of $\mathrm{Hp}$ infection.

\section{Statistical analysis}

The statistical package for social sciences (SPSS) (Inc., Chicago, IL, USA, 22nd version) was used for data input and to analyze the demographic characteristics of the cases. Demographic characteristics were analyzed using basic definitive statistics. A Chi-square test was used to compare every 2 parameters (bile reflux and $\mathrm{Hp}$ infection). A p-value $<0.05$ was deemed statistically significant.
Clinical research ethics committee approval was received from the Ege University Ethics Committee (19-4T/44).

\section{Results}

In our study, 804 cases where all the data were included were enrolled. Of the patients $61.8 \%$ were female and $38.2 \%$ were male. The mean age was $11.56 \pm 4.14$ years. Microscopic and macroscopic analyses of the stomach are shown in Table I.

The number of patients where Hp was detected in the gastrointestinal system was 179 (22.3\%). Among these 179 patients, 89 of them had chronic active mild gastritis, 59 of them had chronic active moderate gastritis, 13 of them had chronic active severe gastritis, 18 of them had chronic mild gastritis.

The prevalence of bile reflux was $23.9 \%(\mathrm{n}=192)$. When evaluated according to age; bile reflux occurred in $14.2 \%$ in the $0-2$ age group, $23.4 \%$ in the 3-6 age group, $19.4 \%$ in the $7-11$ age group, and $27.0 \%$ in the $\geq 12$ age group. Of these 192 cases with bile reflux, 108 of them had chronic mild gastritis, 69 of them had chronic active mild gastritis, 13 of them had chronic active moderate gastritis and 2 of them had chronic active severe gastritis microscopically. Only 27 (14.1\%) patients had Hp positivity among the 192 patients where bile reflux was detected endoscopically ( $\mathrm{p}=0.002)$ (Table II).

\section{Discussion}

Gastric histopathologic findings were normal in $41.7 \%$ of the patients in our study. According to another study that was carried out by Mark et al. ${ }^{13}, 49.0 \%$ of 150 patients had normal histopathologic findings similar to our study. The reason for this may be the small tissue specimen taken during the endoscopic procedure, the involvement being patchy, or perhaps problems such as food allergies or psychosomatic disorders in these patients. 
Table I. Microscopic and macroscopic findings of the stomach.

\begin{tabular}{lcc}
\hline & Frequency $(\mathrm{n})$ & Percent $(\%)$ \\
\hline Macroscopic findings & & 25.5 \\
Normal & 205 & 23.8 \\
Bile reflux & 192 & 18.9 \\
Antral hyperemia & 152 & 18.9 \\
Antral nodularity & 152 & 11.7 \\
Pangastritis & 94 & 1.2 \\
Antral ulceration & 9 & 41.7 \\
Microscopic findings & & 24.8 \\
Normal & 339 & 22.4 \\
Chronic gastritis mild & 201 & 8.6 \\
Chronic active gastritis mild & 181 & 1.6 \\
Chronic active gastritis moderate & 70 & \\
Chronic active gastritis severe & 13 & \\
\hline
\end{tabular}

Table II. The relationship between bile reflux and Hp gastritis.

\begin{tabular}{|c|c|c|c|c|c|}
\hline & & \multicolumn{2}{|c|}{ Helicobacter pylori } & \multirow{2}{*}{ Total } & \multirow{2}{*}{ p-value } \\
\hline & & Positive & Negative & & \\
\hline \multirow{2}{*}{ Bile reflux } & Positive & 27 & 165 & 192 & \\
\hline & Negative & 152 & 460 & 612 & 0.002 \\
\hline Total & & 179 & 625 & 804 & \\
\hline
\end{tabular}

Infections due to $\mathrm{Hp}$, which has a commensal relationship with humans, are usually asymptomatic but may cause symptoms related to peptic ulcer or duodenal inflammation in some individuals. ${ }^{4,5}$ In developing countries, school children are at risk due to low socioeconomic conditions, poor hygienic drinking water, living in crowded conditions, low personal and environmental hygiene, and food contamination. . $^{14,15}$

Hp infection frequency is higher in developing countries than in developed countries. ${ }^{5}$ In our study, $\mathrm{Hp}$ infection frequency was $22.3 \%$. In Africa, this ratio is between $40-90 \%{ }^{16-}$ 19 According to Hunt et al. ${ }^{20}$, while among Ethiopian children between the ages of 1015 the Hp infection prevalence was $82 \%$, this ratio was between $70-90 \%$ in adults. ${ }^{21}$ It was noted that in Canada, Hp infection had a ratio of $7.1 \%$ in children in the age range of $5-18 .^{5}$ This variability maybe because of the different levels of development of these countries. In a local study carried out by Gürakan et al. ${ }^{21}, \mathrm{Hp}$ infection frequency was found to be $52.5 \%$. The decrease in Hp infection after the 2000s was probably a result of the adverse effects of the preservatives and unhealthy oils used in the food industry on bowel movements, and the increase in the use of macrolide group antibiotics may also explain this situation.

Bile reflux was first described in a patient with gastrocutaneus fistula in 1833 and it was perceived as an important problem. ${ }^{22}$ Bile reflux without gastric surgery is called primary bile reflux. The risk factors are gallbladder dysfunction, gastric, and duodenal dysmotility. Due to the decrement of migrating complex motor gastric exposure activity to bile, this causes chemical gastritis and clinical symptoms. The prevalence of bile reflux is unknown. ${ }^{10}$ Radev et al. ${ }^{23}$ found bile reflux prevalence as $10 \%$ in adults. According to Slavesku et al. ${ }^{24}$, 
among children with atrophic gastritis, bile reflux prevalence was found to be $34 \%$. In our study, it was found to be $23.9 \%$. These different ratios may be because of different patient populations. Bile as a strong detergent causes gastric mucosal injury. Histopathologic antral foveolar hyperplasia, vascular congestion, edema in lamina propria, and smooth muscle leave and inflammatory cell shortage can be seen. ${ }^{25}$ In our study, 108 of them had chronic mild gastritis, 69 of them had chronic active mild gastritis, 13 of them had chronic active moderate gastritis and 2 of them had chronic active severe gastritis microscopically. Gastritis was detected microscopically in all patients with bile reflux. Only $14.1 \%$ of patients had Hp positivity among patients with bile reflux $(p=0.002)$. This may be since bile acids have antibacterial activity against Hp.

The changing food industry may have caused a decrease in Hp infections after the 2000s, due to an increase in bile reflux. The increase in the consumption of cheaper and easily accessible take-home foods over time may have caused a decrease in the consumption of healthy foods. Among these unhealthy products, the poor quality high-fat ratio may cause bile reflux by slowing gastric emptying and causing the release of cholecystokinin, with a negative effect on gastrointestinal system motility. ${ }^{26,27}$ Therefore, while $\mathrm{Hp}$ gastritis is investigated in the differential diagnosis of patients with abdominal pain, bile reflux should be included in the differential diagnosis and treatment should be planned accordingly.

\section{Ethical approval}

Ethics committee approval statement was received from Ege University Ethics Committee in 2019 (19-4T/44).

\section{Author contribution}

The authors contribute to the paper as follows: study conception and design: SA, EKT; data collection: FÇ, MS; analysis and interpretation of results: $\mathrm{BD}, \mathrm{MK}$; draft manuscript preparation: EKT, MK, FÇ. All authors reviewed the results and approved the final version of the manuscript.

\section{Source of funding}

The authors declare the study received no funding.

\section{Conflict of interest}

The authors declare that there is no conflict of interest.

\section{REFERENCES}

1. Calvano C, Warschburger P. Chronic abdominal pain in children and adolescents: parental threat perception plays a major role in seeking medical consultations. Pain Res Manag 2016; 2016: 3183562. https://doi.org/10.1155/2016/3183562

2. Korterink JJ, Diederen $\mathrm{K}$, Benninga MA, Tabbers MM. Epidemiology of pediatric functional abdominal pain disorders: a meta-analysis. PLoS One 2015; 10: e0126982. https://doi.org/10.1371/ journal.pone.0126982

3. Horst S, Shelby G, Anderson J, et al. Predicting persistence of functional abdominal pain from childhood into young adulthood. Clin Gastroenterol Hepatol 2014; 12: 2026-2032. https://doi.org/10.1016/j. cgh.2014.03.034

4. Abbas M, Sharif FA, Osman SM, et al. Prevalence and associated symptoms of helicobacter pylori infection among schoolchildren in Kassala State, East of Sudan. Interdiscip Perspect Infect Dis 2018; 2018: 4325752. https://doi.org/10.1155/2018/4325752

5. Iwańczak BM, Buchner AM, Iwańczak F. Clinical differences of Helicobacter pylori infection in children. Adv Clin Exp Med 2017; 26: 1131-1136. https://doi.org/10.17219/acem/60581

6. Kalach N, Bontems P, Raymond J. Helicobacter pylori infection in children. Helicobacter 2017; 22(Suppl 1): e12414. https://doi.org/10.1111/hel.12414

7. Takada K, Hamada Y, Watanabe K, Tanano A, Tokuhara K, Kamiyama Y. Duodenogastric reflux following biliary reconstruction after excision of choledochal cyst. Pediatr Surg Int 2005; 21: 1-4. https://doi.org/10.1007/s00383-004-1251-2 
8. Eldredge TA, Myers JC, Kiroff GK, Shenfine J. Detecting bile reflux-the enigma of bariatric surgery. Obes Surg 2018; 28: 559-566. https://doi.org/10.1007/ s11695-017-3026-6

9. Eldredge TA, Bills M, Myers JC, Bartholomeusz D, Kiroff GK, Shenfine J. HIDA and seek: challenges of scintigraphy to diagnose bile reflux post-bariatric surgery. Obes Surg 2020; 30: 2038-2045. https://doi. org/10.1007/s11695-020-04510-7

10. McCabe ME 4th, Dilly CK. New causes for the old problem of bile reflux gastritis. Clin Gastroenterol Hepatol 2018; 16: 1389-1392. https://doi.org/10.1016/j. cgh.2018.02.034

11. Hyun JJ, Yeom SK, Shim E, et al. Correlation between bile reflux gastritis and biliary excreted contrast media in the stomach. J Comput Assist Tomogr 2017; 41: 696-701. https://doi.org/10.1097/ RCT.0000000000000585

12. Jones NL, Koletzko S, Goodman K, et al; ESPGHAN, NASPGHAN. Joint ESPGHAN NASPGHAN Guidelines for the management of helicobacter pylori in children and adolescents (Update 2016). J Pediatr Gastroenterol Nutr 2017; 64: 991-1003. https://doi.org/10.1097/mpg.0000000000001594

13. Mark JA, Campbell K, Gao D, Kramer RE. Algorithm to predict which children with chronic abdominal pain are low suspicion for significant endoscopic findings. Clin Pediatr (Phila) 2019; 58: 79-87. https:// doi.org/10.1177/0009922818806317

14. Tsongo L, Nakavuma J, Mugasa C, Kamalha E. Helicobacter pylori among patients with symptoms of gastroduodenal ulcer disease in rural Uganda. Infect Ecol Epidemiol 2015; 5: 26785. https://doi. org/10.3402/iee.v5.26785

15. Kimang'a AN, Revathi G, Kariuki S, Sayed S, Devani S. Helicobacter pylori: prevalence and antibiotic susceptibility among Kenyans. S Afr Med J 2010; 100: 53-57.

16. Sathar MA, Gouws E, Simjee AE, Mayat AM. Seroepidemiological study of Helicobacter pylori infection in South African children. Trans R Soc Trop Med Hyg 1997; 91: 393-395. https://doi.org/10.1016/ s0035-9203(97)90253-4

17. Cherian S, Forbes D, Sanfilippo F, Cook A, Burgner D. The epidemiology of Helicobacter pylori infection in African refugee children resettled in Australia. Med J Aust 2008; 189: 438-441. https://doi. org/10.5694/j.1326-5377.2008.tb02116.x
18. Cherian S, Burgner DP, Carson CF, Sanfilippo FM, Cook AG, Forbes DA. Diagnosis of Helicobacter pylori infection in a high-prevalence pediatric population: a comparison of 2 fecal antigen testing methods and serology. J Pediatr Gastroenterol Nutr 2008; 47: 130-135. https://doi.org/10.1097/ MPG.0b013e31815bc5b3

19. Cherian S, Forbes D, Sanfilippo F, Cook A, Burgner D. Helicobacter pylori, helminth infections and growth: a cross-sectional study in a high prevalence population. Acta Paediatr 2009; 98: 860-864. https:// doi.org/10.1111/j.1651-2227.2009.01221.x

20. Hunt RH, Xiao SD, Megraud F, et al. Helicobacter pylori in developing countries. World Gastroenterology Organisation Global Guideline. J Gastrointestin Liver Dis 2011; 20: 299-304.

21. Gürakan F, Koçak N, Yüce A. Helicobacter pylori serology in childhood. Turk J Pediatr 1996; 38: 329334.

22. Beaumont W. Nutrition Classics. Experiments and observations on the gastric juice and the physiology of digestion. By William Beaumont. Plattsburgh. Printed by F. P. Allen. 1833. Nutr Rev 1977; 35 : 144-145. https://doi.org/10.1111/j.1753-4887.1977. tb06570.x

23. Radev D, Kotsev I, Panaĭotov P, et al. The incidence of duodenogastric reflux and its relation to stomach and duodenal diseases. Khirurgiia (Sofiia) 1990; 43: 61-64.

24. Slăvescu KC, Mărgescu C, Pîrvan A, Şarban C, Gheban D, Miu N. Atrophic gastritis: Helicobacter pylori versus duodenogastric reflux. Clujul Med 2013; 86: 138-143.

25. Zhang Y, Yang X, Gu W, Shu X, Zhang T, Jiang $M$. Histological features of the gastric mucosa in children with primary bile reflux gastritis. World J Surg Oncol 2012; 10: 27. https://doi.org/10.1186/14777819-10-27

26. Buscemi S, Barile A, Maniaci V, Batsis JA, Mattina A, Verga S. Characterization of street food consumption in Palermo: possible effects on health. Nutr J 2011; 10: 119. https://doi.org/10.1186/1475-2891-10-119

27. Khodarahmi M, Azadbakht L. Dietary fat intake and functional dyspepsia. Adv Biomed Res 2016; 5: 76. https://doi.org/10.4103/2277-9175.180988 